\title{
Human toxocariosis: is it not a public health problem yet?
}

\begin{abstract}
Brief revision of bibliography about Toxocara during last two years after remind some papers from the author and his group of work at San Marcos University about discussion if Human Toxocariosis should be considered a public health problem. Reminding publications from 2009 to 2016 with this idea and checking some papers showing interest about this infection still important and showing evidences to improve research about clinical manifestations, complications, diagnosis, treatment, prevention, environmental laws, surveillance and other areas to study this parasitic infection. As a conclusion: Human Toxocariosis should be considered a public health problem by sanitary authorities.
\end{abstract}

Volume 2 Issue 4 - 2017

\author{
Pedro Ernesto Huapaya Herreros
}

Regional Hospital of Huacho, Peru

Correspondence: Regional Hospital of Huacho, Jose Arambulo La Rosa No. 25I, Peru, Tel 5 I- I-2322634/5 I-I-232235 I/5 I- I2325754, Email pehuapaya@hotmail.com

Received: December 09, 2017 | Published: December 27, 2017

Keywords: human toxocariosis, revision, public health, research

\section{Introduction}

The main idea of this paper is make a brief revision to discuss why this infection would be considering a public health problem worldwide. Several years ago, exactly in 2009 , I had opportunity to prepare, with some co-researchers at San Marcos University, a paper checking ninety references around the world to discuss importance of human Toxocariosis, we can showed some elements to consider this infection as a public health problem. ${ }^{1}$ We tried to systematize information on Toxocara human infection. Some details about transmission mechanisms, epidemiology, clinical forms, diagnostic methods, treatment and economic costs for public health were described, at the same time, we focused its importance as an infectious cause of blindness in young people that is potentially curable by early diagnosis and its association with asthma and allergies. Then, our proposal was to establish epidemiological surveillance, improve current laws to reduce transmission risk to the general population and increase knowledge on this infection in our country, Peru and of course the rest of the world. Later, in 2010, my friend William Roldan and our work group we prepared another paper checking diagnosis of the infection. ${ }^{2}$ In that paper we described again infection with more details in description to update the available knowledge on the use of different tools for both the diagnosis and following up of human Toxocariosis. Our main idea was to emphasize that is possible detect infection and give treatment early. Our interest about this infection continued so hard, and by this reason, in 2016 we published another paper with other friends checking prevalence of human Toxocariosis in a group of people of some provinces of Lima Region, next to Lima Metropolitan, capital city of our country. ${ }^{3}$ In this work we found $32 \%$ of sera samples positive to Toxocara, $54 \%$ were female and $31 \%$ were between $31-59$ years old, this data confirmed that Toxocara infection is frequent in Lima, so we can presumed that was more frequent in rural region of our country. Several years has passed and we still have interest to know if sanitary authorities could consider this infection as a public health problem, in order to discuss and improve rules to promote surveillance, detection, early diagnosis and treatment to prevent high economic costs with blindness, asthma, allergies, and attention derivatives from them. Our interest for this infection moved me to check some references, abstracts and papers from this year 2017 and previous 2016 using Pub Med. I found one from October 2017, it is an African revision similar as ours with fifty five papers to conclude that several points about Toxocara infection have never been systematically evaluated, ${ }^{4}$ another papers, ${ }^{5,6}$ make some recommendations for future research towards the prevention and control of this important disease. There are several experiences checking human infection by sero diagnosis in different countries ${ }^{7-9}$ with prevalence between $5 \%$ to $13 \%$ in United States and $37 \%$ in Nigeria. Several diagnostic methods have been used with different technologies as recombinant antigens ${ }^{10,11}$ dot ELISA $^{12}$ or ELISA and $\mathrm{PCR}^{13}$ And the association with allergy and asthma, ${ }^{14-16}$ ocular disease ${ }^{16,17}$ and presence in playgrounds ${ }^{18-20}$ is cause of interest for some researchers.

\section{Conclusion}

All these evidences improve efforts to get human Toxocara infection would be considered as a public health problem worldwide and stimulates researches to get better elements to prevent its consequences.

\section{Acknowledgements}

This paper could not be possible without help of all members of the Parasitology Section of "Daniel A. Carrion" Tropical Medicine Institute from San Marcos University, where I developed my interest for infectious diseases and research many years ago.

\section{Conflict of interest}

Author do not have any conflict of interest because all papers mentioned in this paper were prepared as part of university projects. His paper is useful to recognize work of many value people

\section{References}

1. Huapaya P, Espinoza Y, Roldan W, et al. Human toxocariasis: public health problem? An Fac Med. 2009;70(4):203-290.

2. Roldan W, Espinoza Y, Huapaya P, et al. The diagnosis of human Toxocariosis. Rev Peru Med Exp Public Health. 2010;27(4):613-620.

3. Espinoza Y, Vildózola H, Jimenez S, et al. Estimated prevalence of human toxocariosis in the Lima An Fac med RegionEstimated prevalence of human toxocariosis in the Lima. An Fac med Region. 2016;77(1):21-24. 
4. Lötsch F, Vingerling R, Spijker R, et al. Toxocariasis in human in Africa-A systematic review. Travel Med Infect Dis. 2017;20:15-20.

5. Ma G, Holland C, Wang T, et al. Human toxocariasis. Lancet Infect dis. 2017;18(1):e14-e24.

6. Duréault A, Perez C, Weber L, et al. Toxocariasis, a neglected disease in Switzerland? Rev Med. 2017;13(558):815-819.

7. Liu E, Chastain H, Shin S, et al. Seroprevalence of antibodies to Toxocara species in the United States and associated risk factors, 2011-2014. Clin Infect Dis. 2017;66(2):206-212.

8. Berret A, Erickson L, Gale S, et al. Toxocara seroprevalence and associated risk factors in the United States. Am J Trop Med Hyg. 2017;97(6):1846-1850.

9. Sowemimo O, Lee Y, Asaolu S, et al. Seroepidemiological study and associated risk factors of Toxocara canis infection among preshool children in Osun State, Nigeria. Acta Trop. 2017;173:85-89.

10. Varghese A, Raina O, Chandra D, et al. Sero-detection of Toxocara canis infection in humans with T.canis recombinant arginine kinase, cathepsin L-1 and TES-26 antigens. Acta Parasitol. 2017;62(4):775-778.

11. Yunus M, Tan Farrizam S, Abdul Karim I, et al. A lateral flow rapid test for human Toxocariasis developed using three Toxocara canis recombinant antigens. Am J Trop Med Hyg. 2017;98(1):32-38.

12. Paller V, Besana C, Valdez I. Dot enzyme-linked immunosorbent assay (ELISA) for the detection of Toxocara infection using a rat model. $J$ Parasit Dis. 2017;41(4):933-939.
13. Mc Kenna M, Mc Atee S, Bryan P, et al. Human intestinal parasite burden and poor sanitation in rural Alabama. Am J Trop Med Hyg. 2017;97(5):1623-1628.

14. Silva M, Amor A, Santos L, et al. Risk factors for Toxocara spp. Seroprevalence and its association with atopy and asthma phenotypes in school-age children in a small town and semi-rural areas of Northeast Brazil. Acta Trop. 2017;174:158-164.

15. Cadore $\mathrm{P}$, Zhang L, Lemos L, et al. Toxocariosis and childhood asthma: a case-control study. J Asthma. 2016;53(6):601-616.

16. Rubinsky G, Yamamoto J, Hirata C, et al. Toxocariasis: critical analysis of serology in patients attending a pubblic referral center for ophthalmology in Brazil. Jpn J Ophthalmol. 2018;62(1):77-83..

17. Yoon D, Woo S. Intravitreal administration of Ranibizumab and Bevacizumab for choroidal neovascularization secondary to ocular Toxocariasis: a case report. Ocul Immunol Inflamm. 2016;24:1-3.

18. Otero D, Alh A, Niisse R, et al. Environmental contamination with Toxocara spp. Eggs in public parks and playground sandpits of Greater Lisbon, Portugal. J Infect Public Health. 2017. p. 94-98.

19. Kleine A, Springer A, Strube C. Seasonal variation in the prevalence of Toxocara eggs on children's playgrounds in the city of Hannover, Germany. Parasite and Vectors. 2017;10:248.

20. Rivero M, De Angelo C, Nuñez P, et al. Environmental and sociodemographic invidivual, family and neighborhood factors associated with children intestinal parasitoses at Iguazu, in the subtropical northern border of Argentina. Neglected Tropical Diseases. 2017;(20):1-26. 